\title{
An Optimal Allocation Model of Public Transit Mode Proportion for the Low-Carbon Transportation
}

\author{
Linjun Lu, ${ }^{1}$ Chen Wang, ${ }^{2}$ Weiping Deng, ${ }^{1}$ and Xue Bing ${ }^{3}$ \\ ${ }^{1}$ Shanghai Jiao Tong University, School of Naval, Architecture, Ocean, and Civil Engineering, 800 Dongchuan Road, \\ Mulan Building A906, Shanghai 200240, China \\ ${ }^{2}$ Tongji University, School of Transportation Engineering, 4800 Cao-An Highway, Shanghai 201804, China \\ ${ }^{3}$ Shenyang Urban Planning Design \& Research Institute, No. 1 Nan-San-Hao Street, Shenyang, Liaoning 110004, China
}

Correspondence should be addressed to Chen Wang; wkobec@hotmail.com

Received 18 July 2014; Accepted 10 November 2014

Academic Editor: Hong Chen

Copyright (C) 2015 Linjun Lu et al. This is an open access article distributed under the Creative Commons Attribution License, which permits unrestricted use, distribution, and reproduction in any medium, provided the original work is properly cited.

Public transit has been widely recognized as a potential way to develop low-carbon transportation. In this paper, an optimal allocation model of public transit mode proportion (MPMP) has been built to achieve the low-carbon public transit. Optimal ratios of passenger traffic for rail, bus, and taxi are derived by running the model using typical data. With different values of traffic demand, construction cost, travel time, and accessibilities, MPMP can generate corresponding optimal ratios, benefiting decision impacts analysis and decision makers. Instead of considering public transit as a united system, it is separated into units in this paper. And Shanghai is used to test model validity and practicality.

\section{Introduction}

With increasingly severe global warming problem, low carbon development comes into view. According to the 2009 report "Transport, energy and $\mathrm{CO}_{2}$, Moving towards sustainability" from U.S. Energy Information Administration (EIA), transportation has taken responsibility for about $25 \%$ of global $\mathrm{CO}_{2}$ emissions and become the third industry of $\mathrm{CO}_{2}$ emissions following the power and petrochemical industries [1]. It requires a quick and effective action to reduce $\mathrm{CO}_{2}$ emissions from transportation. Public transit has been widely recognized as an effective way to reduce greenhouse gas (GHG) emissions, decrease energy consumption, improve mobility, and cut traffic congestion [2], which is also the study object of this paper.

Public transit is the first choice of low-carbon transportation because it possesses large capacity and low carbon emissions per capita. There are two popular research aspects in this field: its potential to reduce GHG emissions and comparison with other means. Public transit is used to be studied as a united system in previous studies, yet it is comprised of various modes of transportation. This paper answers how to achieve the low-carbon public transit and the specific proportions of various modes.

This paper is targeted to minimize $\mathrm{CO}_{2}$ emissions with optimal ratios of passenger traffic for different public transit modes (rail, bus, and taxi are covered here). An optimal allocation model of public transit mode proportion (MPMP) is built and Shanghai has been taken as a study case. As MPMP can provide optimum ratios with different values of traffic demand, construction cost, travel time, and accessibilities, it will not only allocate passenger traffic for the lowest $\mathrm{CO}_{2}$ emissions but also benefit decision impacts analysis and decision makers.

In the following sections, literature review of public transportation and GHG emissions will be first provided. Then this paper will present the modeling process of MPMP. Lastly, Shanghai will be taken as a study case to explore and promote the application of it.

\section{Literature Review}

The public transit's potential to reduce GHG emissions is widely studied. The study of Yoshida and Harata [3] showed 
that shifting travelers' travel mode from private car to public transport was one effective method to reduce $\mathrm{CO}_{2}$ emissions and ease traffic congestion. Li and Tamura [4] achieved the same result by developing a $\mathrm{CO}_{2}$ emissions forecasting model to estimate the amount of $\mathrm{CO}_{2}$ emissions on urban commute travel.

More latter literatures tried to compare the public transit with many other traffic modes in terms of $\mathrm{CO}_{2}$ emissions reduction. Bose [5] considered three scenarios, including business as usual, motor vehicle use, and public transit, and results of the experiments conducted in three South Asian cities showed that slower vehicle and energy growth measures based on the public transit scenario were most effective in emission reduction. Hickman et al. [6] assumed a series of potential emissions mitigation policy packages implemented in London in 2025 to achieve the carbon-efficient transportation. It included low-emission vehicles, alternative fuels, walking and cycling, information, and communication technologies, and public transit was one of them. Mostashari et al. [7] supposed 28 different emission reduction strategies and combined demand modeling, fleet evolution modeling, mobile-source emissions modeling, and trade-off analysis to evaluate the impact of these emission reduction strategies. He et al. [8], Feng et al. [9], and Wayne et al. [10] completed the approximate comparison through different models, respectively.

Considering that the objective function in those studies mentioned above did not take "cost" into account, Gallivan et al. [11] compared a comprehensive range of strategies in terms of three potential GHG reductions and cost effectiveness, in dollars per ton of GHG emissions reduced, and cost here consisted of labor costs, fuel prices, metro costs and revenues, and so forth. The aim of Gallivan's paper was to find the costeffective approaches to reduce greenhouse gas emissions through public transportation in Los Angeles. Cost of different measures is also under the consideration of Maciel et al. [12] and Damart and Roy [13].

Most studies regard the public transit as a united system when analyzing $\mathrm{CO}_{2}$ emissions, while this paper plans to deal with public transit itself which possesses various modes of transportation. The subject being addressed here belongs to the general category of resources allocation problem which has been involved in transportation. Huang et al. [14] explored the optimal allocation of multiple emergency service resources for protection of critical transportation infrastructure through a mixed integer linear programming model, limited emergency service here referring to the fire engines, fire trucks, and ambulances, in which the objective was to maximize the service coverage to the critical transportation infrastructures. Fan and MacHemehl [15] presented a bilevel optimization model for the public transportation network redesign to solve the spatial equity issue, in which the upperlevel subprogram was to minimize the total cost and the lower-level subprogram was a user self-routing optimization. Orabi and El-Rayes [16] allocated limited financial resources to competing highway rehabilitation projects through an innovative model and Barnum et al. [17] developed a procedure estimating resources allocation efficiency among transit types based on data envelopment analysis.

\section{Modeling}

What should the proportion of different modes of public transit be in order to gain the lowest $\mathrm{CO}_{2}$ emissions? In order to find out the answer to this question, an optimal allocation model has been built in this section. By inputting some gettable and typical data, the optimal allocation model can generate the optimum ratios of passenger traffic that rail transit, bus, and taxi should undertake separately.

3.1. Research Object. Public transit generally includes rail transit, bus rapid transit (BRT), bus, taxi, ferry, and public bicycle. Since the use of BRT and ferry is not widespread, and public bicycle contributes nothing to $\mathrm{CO}_{2}$ emissions, this paper selects rail transit, bus, and taxi as the research object.

3.2. Objective Function. Take the minimum of $\mathrm{CO}_{2}$ emissions as the target and the average daily passenger traffic rail transit, bus, and taxi sharing as the decision variables. The product of the carbon emissions factor $\left(K_{i}\right)$, the average riding distance $\left(r_{i}\right)$, and the average daily passenger traffic $\left(x_{i}\right)$ is, namely, $\mathrm{CO}_{2}$ emissions, and the sum $(Z)$ of rail transit, bus, and taxi $\mathrm{CO}_{2}$ emissions gives the objective function as formula (1).

3.3. Constraint Conditions. The characteristic of rail transit, bus, and taxi are mainly different in capacity, cost, speed, accessibility, and comfortableness. As the decision variables (the average daily passenger traffic they share) are not involved with vehicle equipment, and comfortableness varies from person to person, capacity and comfortableness are out of consideration. There are finally four constraints for the model as follows.

(1) Meeting the Traffic Demand. The average daily passenger traffic $\left(x_{i}\right)$ rail transit, bus, and taxi each take must meet city's total traffic demand $(D)$ for public transit, which generates formula (2).

(2) Restrictions on Construction Cost. The cost of public transit includes construction and operating cost, and the latter is ignored here due to its uncertainty and hardness to obtain. Rail transit owns the highest construction cost. As bus and taxi take use of urban road resources, their construction cost is hard to measure, yet definitely much lower than rail transit's. So the construction cost of rail transit is chosen to be one of the constraints.

The aggregate investment amount $(I)$ is taken in the formula. And the average daily passenger flow intensity $(p)$ is introduced to combine the cost with the passenger traffic. The ratio of $x_{1}$ (rail transit's average daily passenger traffic) and $p$ is the corresponding length of the rail transit. The product of the length and the construction cost of unit length $(c)$ should not be more than $I$, as it is shown in formula (3).

(3) Ensuring the Travel Time. Rail transit is cheaper than taxi, more comfortable than bus, and sometimes even faster than both of taxi and bus, so people would like to take it and the average riding distance $\left(r_{1}\right)$ is normally larger, which makes it unreasonable to compare average travel time of the three 
modes simply. For the consideration of travel time, this paper uses the reciprocals of their speeds $\left(t_{i}, t_{i}=1 / v_{i}\right)$ for modeling.

And the peak hour speeds are chosen for the consideration of the worst situation. Since rail transit has its own independent operation space and bus and taxi run on the urban roads with other vehicles, it may enhance the advantage of rail transit. However, rail transit also owns the advantage of large capacity and low carbon emissions. Therefore, this way of dealing with the speed data can not only ensure the content of traffic demand, but also a low-carbon result, which is exactly what this paper expects.

For the sake of passengers' requirement for travel time, the parameter $T$ is adopted to restrict the average travel time of unit distance, shown in formula (4).

(4) Considering the Accessibility. Accessibility means the degree of difficulty for one to reach some place. Due to the low ration of stop coverage, rail transit owns the worst accessibility. And taxi owns the best accessibility, because it stops whenever there is a call. Bus' accessibility is better than rail transit and worse than taxi.

The connecting time $\left(s_{i}\right)$ a passenger needs from his origin to the nearest stop of rail transit, bus, or taxi is taken on behalf of the accessibility. The parameter $S$ is adopted to restrict the average connecting time to ensure the level of public transit services, as in formula (5).

3.4. Model. According to the process above, an optimal allocation model of public transit mode proportion (MPMP) for the lowest public transit $\mathrm{CO}_{2}$ emissions has been accomplished as follows:

$$
\text { Minimize } \quad Z=\sum_{i=1}^{3} K_{i} r_{i} x_{i}
$$

subject to

$$
\begin{aligned}
& \sum_{i=1}^{3} x_{i}=D, \\
& \frac{x_{1}}{p} \times c \leq I, \\
& \frac{\sum_{i=1}^{3} t_{i} x_{i}}{\sum_{i=1}^{3} x_{i}} \leq T, \\
& \frac{\sum_{i=1}^{3} s_{i} x_{i}}{\sum_{i=1}^{3} x_{i}} \leq S,
\end{aligned}
$$

where

\footnotetext{
$Z$ is the average daily $\mathrm{CO}_{2}$ emissions from public transit (kg);

$i$ is the $i$ th kind of public transit ( $i=1$, rail transit; $i=2$, bus; $i=3$, taxi);

$K_{i}$ is the $\mathrm{CO}_{2}$ emissions factor of the $i$ th kind of public transit (kg/km·trip);

$r_{i}$ is the average riding distance of the $i$ th kind of public transit $(\mathrm{km})$;
}

$x_{i}$ is the average daily passenger traffic of the $i$ th kind of public transit (trip);

$D$ is the total daily passenger traffic of public transit (trip);

$p$ is the average daily passenger flow intensity of rail transit (trip/km);

$c$ is the rail transit's construction cost of unit length (Yuan/km);

$I$ is the aggregate investment amount (Yuan);

$t_{i}$ is travel time per kilometer of the $i$ th kind of public transit $(\mathrm{min} / \mathrm{km})$;

$T$ is the upper limit of the average travel time per kilometer $(\mathrm{min} / \mathrm{km})$;

$s_{i}$ is the connecting time of the $i$ th kind of public transit (min);

$S$ is the upper limit of the average connecting time (min).

\section{Case Study}

4.1. Scenario Building. Shanghai is taken as a study case to build several scenarios for the model's application. There are five scenarios in all, and each scenario considers two cases, respectively.

(1) Scenario 0 (SO) and Scenario $0^{\prime}\left(S O^{\prime}\right)$. This scenario represents the situation of Shanghai in 2009. S0 uses the actual public transit proportion to calculate the actual $\mathrm{CO}_{2}$ emissions directly. And $\mathrm{S}^{\prime}$ takes the public transit situation to run the optimal allocation model. Output comparison of S0 and $\mathrm{SO}^{\prime}$ can tell us whether the model generates a reasonable result.

(2) Scenario 1 (S1) and Scenario $1^{\prime}\left(S 1^{\prime}\right)$. This scenario represents the situation of Shanghai in 2020, assuming no progress in vehicle technology, no additional management in urban roads, and no development of public transit. With the growth of the city, the traffic demand and the average riding distance of public transit are supposed to increase. Because there is no additional management in urban roads, the outbreak of motor vehicle will reduce the service level of urban roads, resulting in the lower speeds of bus and taxi. Given the above analysis, a normal restrict level of the travel time for S1 and a lower restrict level of the travel time (which means people can stand a longer travel time) for $\mathrm{S1}^{\prime}$ are adopted.

(3) Scenario 2 (S2) and Scenario $2^{\prime}\left(S 2^{\prime}\right)$. This scenario builds on $S 1$ by assuming thorough management in urban roads. The management in urban roads will improve the service level of urban roads, so bus and taxi will be faster, too. In order to complete an easier comparison between $\mathrm{S}^{\prime}$ and $\mathrm{S} 2$, the lower restrict level of the travel time (as in $\mathrm{S}^{\prime}$ ) for $\mathrm{S} 2$ and the normal restrict level of the travel time (as in S1) for $\mathrm{S}^{\prime}{ }^{\prime}$ should be taken into account. 
TABLE 1: Parameter value changes in different scenarios.

\begin{tabular}{|c|c|c|c|c|c|c|c|c|c|c|c|c|}
\hline \multirow{2}{*}{ Scenario } & \multirow{2}{*}{ Time } & \multicolumn{11}{|c|}{ The parameter value } \\
\hline & & $K_{i}$ & $r_{i}$ & $D$ & $p$ & $c$ & $I$ & $v_{i}$ & $t_{i}$ & $T$ & $s_{i}$ & $S$ \\
\hline S0 & 2009 & - & - & \multicolumn{9}{|c|}{ Calculate with the actual public transit proportion } \\
\hline $\mathrm{S}^{\prime}$ & 2009 & - & - & - & - & - & - & - & - & - & - & - \\
\hline S1 & 2020 & - & $\uparrow$ & $\uparrow$ & - & - & - & $v_{2} \& v_{3} \downarrow$ & $t_{2} \& t_{3} \uparrow$ & - & - & - \\
\hline $\mathrm{S1}^{\prime}$ & 2020 & - & $\uparrow$ & $\uparrow$ & - & - & - & $v_{2} \& v_{3} \downarrow$ & $t_{2} \& t_{3} \uparrow$ & $\uparrow$ & - & - \\
\hline S2 & 2020 & - & $\uparrow$ & $\uparrow$ & - & - & - & $v_{2} \& v_{3} \uparrow$ & $t_{2} \& t_{3} \downarrow$ & $\uparrow$ & - & - \\
\hline $\mathrm{S} 2^{\prime}$ & 2020 & - & $\uparrow$ & $\uparrow$ & - & - & - & $v_{2} \& v_{3} \uparrow$ & $t_{2} \& t_{3} \downarrow$ & - & - & - \\
\hline S3 & 2020 & - & $\uparrow$ & $\uparrow$ & - & $\uparrow$ & $\uparrow$ & $v_{2} \& v_{3} \uparrow$ & $t_{2} \& t_{3} \downarrow$ & - & $s_{1} \& s_{2} \downarrow$ & - \\
\hline$S 3^{\prime}$ & 2020 & - & $\uparrow$ & $\uparrow$ & - & $\uparrow$ & $\uparrow$ & $v_{2} \& v_{3} \uparrow$ & $t_{2} \& t_{3} \downarrow$ & - & $s_{1} \& s_{2} \downarrow$ & $\downarrow$ \\
\hline S4 & 2020 & $K_{2} \& K_{3} \downarrow$ & $\uparrow$ & $\uparrow$ & - & $\uparrow$ & $\uparrow$ & $v_{2} \& v_{3} \uparrow$ & $t_{2} \& t_{3} \downarrow$ & - & $s_{1} \& s_{2} \downarrow$ & $\downarrow$ \\
\hline
\end{tabular}

Note: "-" means the base value. " not mentioned in the same cell take the base value.

(4) Scenario 3 (S3) and Scenario $3^{\prime}\left(S 3^{\prime}\right)$. This scenario builds on S2 by considering rapid development of public transit, which will enhance the accessibility of rail transit and bus. A normal restrict level of the accessibility for S3 and a higher restrict level of the accessibility (which means people require a better accessibility, so the upper limit of the average connecting time falls) for $\mathrm{S}^{\prime}$ are used.

(5) Scenario 4 (S4). This scenario builds on S3 by adding the promotion of the "Oil replaced by Gas" project. Because of the promotion of the "Oil replaced by Gas" project, the $\mathrm{CO}_{2}$ emissions factor of bus and taxi will decrease. The higher restrict level of the accessibility (as in S3') for S4 is considered.

The parameter value changes in different scenarios are clearly summarized in Table 1.

The average riding distances of rail transit, bus, and taxi are mainly influenced by the city scale, the progress of urbanization, and the city land use properties; thus this paper assumes that the average riding distances will increase in 2020 but remain unchanged in 2020 scenarios, which means S1, S1', $\mathrm{S} 2, \mathrm{~S} 2^{\prime}, \mathrm{S} 3, \mathrm{~S}^{\prime}$, and $\mathrm{S} 4$ share the same $r_{i}$. Besides, this paper uses the same average daily passenger flow intensity of rail transit in different scenarios to ensure the comfortableness of rail transit and the comparability of different scenarios' outputs.

\subsection{Data Acquisition and Processing}

(1) The $\mathrm{CO}_{2}$ Emissions Factor $\left(K_{i}\right)$. The base values for $\mathrm{CO}_{2}$ emissions factors of rail transit, bus, and taxi are $0.042 \mathrm{~kg} /$ $\mathrm{km} \cdot$ trip, $0.069 \mathrm{~kg} / \mathrm{km} \cdot$ trip, and $0.200 \mathrm{~kg} / \mathrm{km} \cdot$ trip, respectively [18]. After the promotion of the "Oil replaced by Gas" project, $\mathrm{CO}_{2}$ emissions factors of bus and taxi are calculated as follows.

$\mathrm{CO}_{2}$ Emissions Factor of Bus. With the empirical data of $30 \mathrm{~L}$ consumption of fuel and $33 \mathrm{~L}$ consumption of gas per $100 \mathrm{~km}$, the amount of $\mathrm{CO}_{2}$ emissions that a bus produces per $100 \mathrm{~km}$ are $69.3 \mathrm{~kg}$ and $11.88 \mathrm{~kg}$, respectively, so $\mathrm{CO}_{2}$ emissions factors of bus for fuel and gas are $0.069 \mathrm{~kg} / \mathrm{km}$.trip and $0.012 \mathrm{~kg} / \mathrm{km} \cdot$ trip, respectively. After the promotion of the "Oil replaced by Gas" project, the regular buses reduce $83 \%$ of $\mathrm{CO}_{2}$ emissions, and the electric buses do not produce $\mathrm{CO}_{2}$ emissions. As we know, there are 16272 buses in Shanghai in 2009 which contains about 150 electric buses [19]. Assuming that there are $20 \%$ of the buses participating in the "Oil replaced by Gas" project and $10 \%$ of the buses using electric, then $\mathrm{CO}_{2}$ emission factors of bus reduces to $0.050 \mathrm{~kg} / \mathrm{km} \cdot$ trip.

$\mathrm{CO}_{2}$ Emissions Factor of Taxi. There are 49 thousand taxies in Shanghai in 2009 [19], 40 thousand of which can participate in the "Oil replaced by Gas" project with some equipment. Assuming that $50 \%$ of the taxies participate in the project in 2020, then $\mathrm{CO}_{2}$ emissions factor of taxi reduce to $0.116 \mathrm{~kg} / \mathrm{km} \cdot$ trip.

(2) The Average Riding Distances $\left(r_{i}\right)$. The average trip distances of Shanghai in 1995, 2004, and 2009 are $4.5 \mathrm{~km}, 6.2 \mathrm{~km}$, and $6.5 \mathrm{~km}$, respectively, and the average riding distances of rail transit, bus, and taxi of Shanghai in 2009 are $17.8 \mathrm{~km}$, $9.1 \mathrm{~km}$, and $6.1 \mathrm{~km}$ [19]. According to the development of the city, estimating the average trip distance of Shanghai in 2020 to be $8.2 \mathrm{~km}$, the average riding distances of rail transit, bus, and taxi will be $22.5 \mathrm{~km}, 11.5 \mathrm{~km}$, and $7.7 \mathrm{~km}$ in 2020 .

(3) The Total Daily Passenger Traffic (D). The total daily passenger traffic of public transit of Shanghai in 1995, 2000, 2004, 2007, and 2009 are 10.28 million trips, 9.75 million trips, 12.01 million trips, 12.37 million trips, and 14.07 million trips [19], so the total daily passenger traffic in 2020 is estimated 25.02 million trips.

(4) The Average Daily Passenger Flow Intensity of Rail Transit (p). The average daily passenger flow intensity of rail transit is 14.3 thousand trips $/ \mathrm{km}$, and the aggregate investment amount of Shanghai in 2009 [19] is 167.8 billion Yuan. According to the total length of the rail transit in Shanghai in 2009, the rail transit's construction cost can be estimated around 0.5 billion Yuan per $\mathrm{km}$. It is said that the aggregate investment amount of Shanghai in 2020 can reach 630 billion Yuan, so the rail transit's construction cost can be estimated around 0.7 billion Yuan per km. 


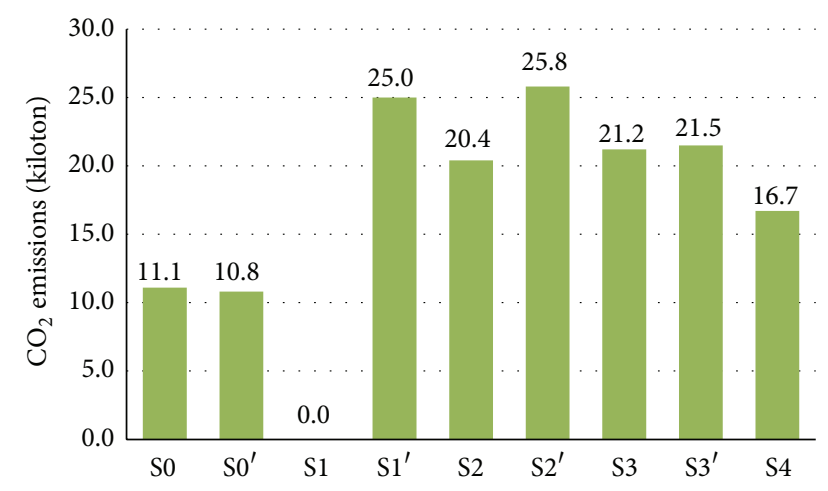

FIGURE 1: Optimum ratios of passenger traffic volume of rail transit, bus, and taxi.

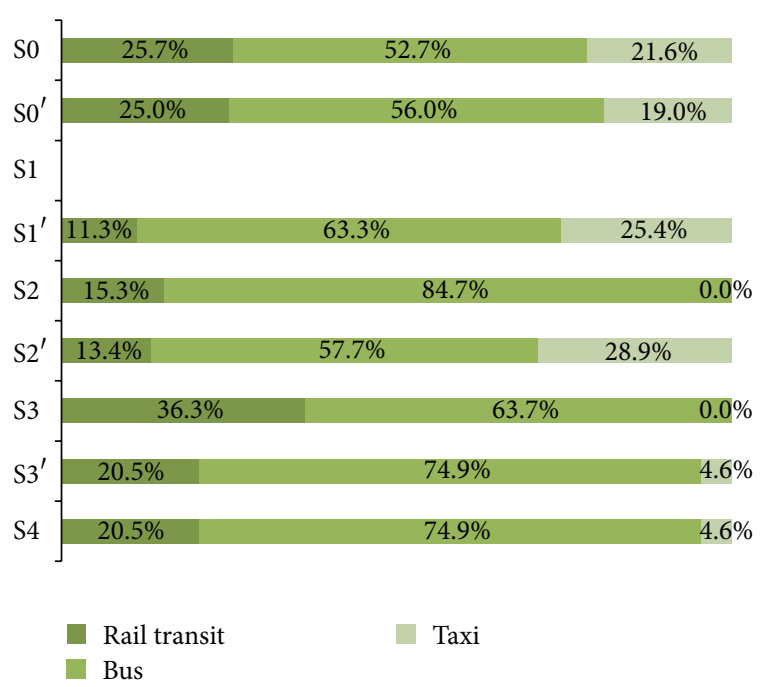

Figure 2: The lowest $\mathrm{CO}_{2}$ emissions for each scenario.

(5) The Speeds $\left(v_{i}, t_{i}=1 / v_{i}\right)$. The speeds of rail transit, bus, and taxi for Shanghai in 2009 are $35.1 \mathrm{~km} / \mathrm{h}, 14.0 \mathrm{~km} / \mathrm{h}$, and $17.0 \mathrm{~km} / \mathrm{h}$ [19]. If there is no management in the urban roads, the speeds of bus and taxi are estimated to reduce to $9.0 \mathrm{~km} / \mathrm{h}$ and $11.0 \mathrm{~km} / \mathrm{h}$. And if there is thorough management in the urban roads, the speeds of bus and taxi are expected to rise up to $15.0 \mathrm{~km} / \mathrm{h}$ and $18.0 \mathrm{~km} / \mathrm{h}$.

(6) The Connecting Times $\left(s_{i}\right)$. The connecting times of rail transit, bus, and taxi of Shanghai in 2009 are $39 \mathrm{~min}, 12 \mathrm{~min}$, and $8 \mathrm{~min} \mathrm{[19].} \mathrm{If} \mathrm{there} \mathrm{is} \mathrm{a} \mathrm{rapid} \mathrm{development} \mathrm{of} \mathrm{public}$ transit, the connecting times of rail transit and bus are considered to reduce to $30 \mathrm{~min}$ and $10 \mathrm{~min}$.

The parameter values in each scenario are summarized in Table 2.

4.3. Results and Analysis. Using Matlab for the calculation of MPMP, the optimum ratios of rail transit, bus, and taxi, and the lowest $\mathrm{CO}_{2}$ emissions for all the scenarios that MPMP generates is graphically shown in Figures 1 and 2.
So versus $\mathrm{SO}^{\prime}$. Using the actual public transit proportion of Shanghai in 2009, the amount of $\mathrm{CO}_{2}$ emissions in $\mathrm{S} 0$ is 11.1 kilotons. In $\mathrm{S}^{\prime}$, the public transit situation of Shanghai in 2009 is taken into the optimal allocation model to obtain the amount of $\mathrm{CO}_{2}$ emissions under the normal restrict level of the travel time and the accessibility $(T=3.5, S=18)$, which turns out to be 10.8 kilotons. Higher ratio of bus and lower ratio of taxi is the major difference between the actual public transit proportion and MPMP's proposed values for the optimum ratios of rail transit, bus, and taxi, which is easy to understand because taxi owns the highest $\mathrm{CO}_{2}$ emissions per capita. That is to say, MPMP's proposed values have the same trend as the actual situation and the difference between them owns a reasonable explanation. In addition, the proposed amount of $\mathrm{CO}_{2}$ emissions is lower than the actual situation's. So the conclusion can be drawn that MPMP's output result accords with practice and the model owns a high reliability. Based on MPMP's output result, taxi is the key for Shanghai to reduce $\mathrm{CO}_{2}$ emissions of public transit. The government should lead people to choose bus over taxi for a trip.

S1. Under the normal restrict level of the travel time and the accessibility $(T=3.5, S=18)$, MPMP cannot generate feasible solution for S1. That is because the service level of public transit cannot reach the normal requirements any more with the rapid rise of the travel demand and no development of urban roads or public transit. It proves the accuracy of the model in some extent.

$S 1^{\prime}$ versus $S 2 . \mathrm{S1}^{\prime}$ reduces the restrict level of the travel time $(T=5.8)$ and gets the lowest amount of $\mathrm{CO}_{2}$ emissions 25.0 kilotons. Due to thorough management in urban roads in S2, the speeds of bus and taxi are enhanced to achieve the lowest amount of $\mathrm{CO}_{2}$ emissions 20.4 kilotons. Under the same restrict level of the travel time and the accessibility $(T=5.8$, $S=18$ ), it can be deemed that management in the urban roads can help with the reduction of $\mathrm{CO}_{2}$ emissions.

S2 versus $S 2^{\prime}$. The reduction in the restrict level of the travel time in $\mathrm{S} 2$ leads to the propose value 0 for taxi. We recover the restrict level of the travel time $(T=3.5)$ in S2 ${ }^{\prime}$ and obtain the lowest amount of $\mathrm{CO}_{2}$ emissions to be 25.8 kilotons which is larger than that in S2. It is thus clear that the amount of $\mathrm{CO}_{2}$ emissions rises along with the rising restrict level of the travel time, which is logical and proves the accuracy of the model as well.

$S 2^{\prime}$ versus $S 3$. S3 develops public transit rapidly and enhances the accessibility of rail transit and bus. The lowest amount of $\mathrm{CO}_{2}$ emissions in $\mathrm{S} 3$ turns out to be 21.2 kilotons, less than that in $\mathrm{S}^{\prime}{ }^{\prime}$. Under the same restrict level of the travel time and the accessibility ( $T=3.5, S=18$ ), it can be seen that development of public transit can help reduce $\mathrm{CO}_{2}$ emissions.

S3 versus S3 ${ }^{\prime}$. The proposed value for taxi in S3 is 0 , so it is obvious that the restrict level of the accessibility can be enhanced in this situation. We improve the restrict level of the accessibility $(S=14)$ and get the lowest amount of $\mathrm{CO}_{2}$ emissions 21.5 kilotons, more than that in S3, which is also logical and proves the accuracy of the model further. 


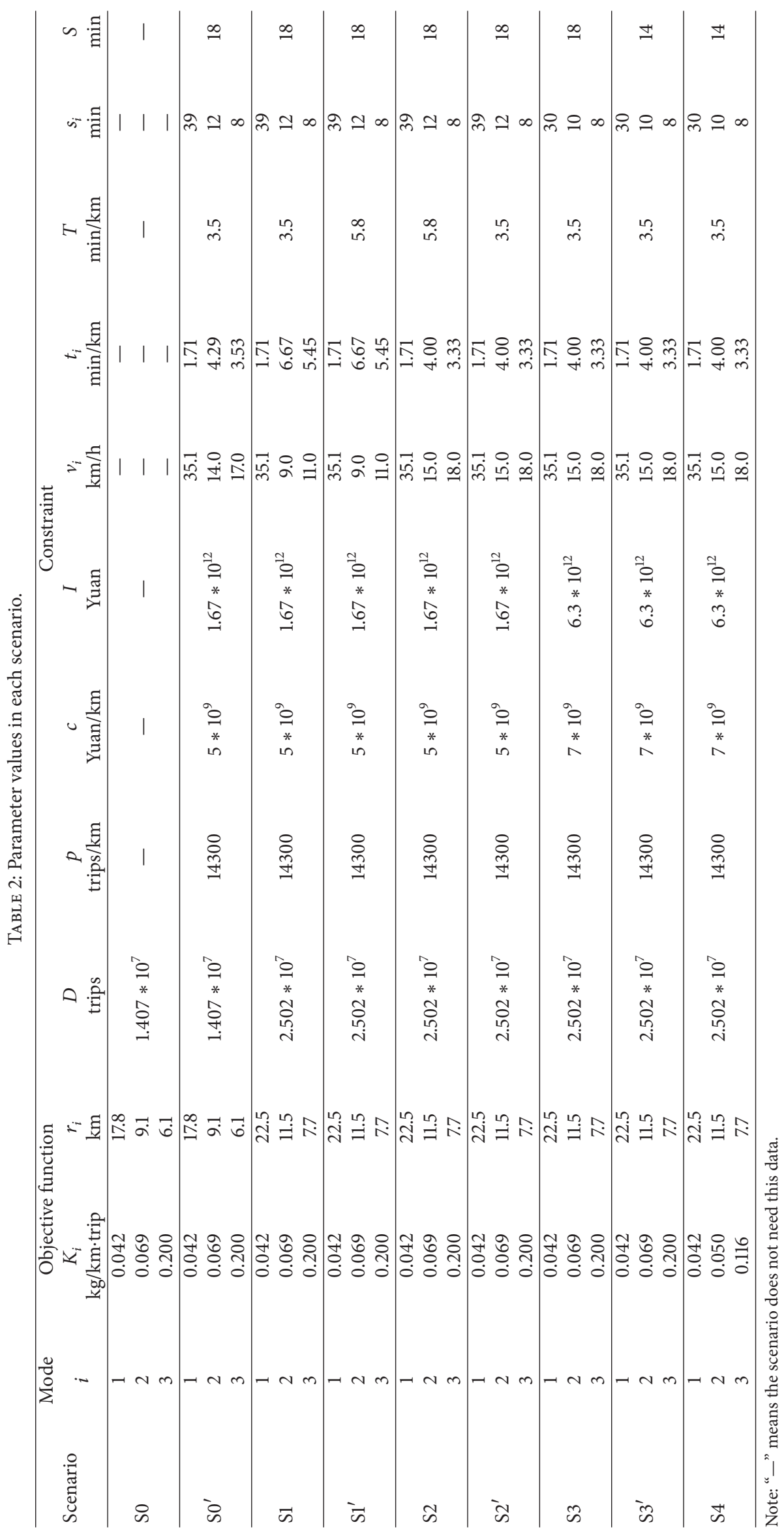


$S 3^{\prime}$ versus S4. The lowest amount of $\mathrm{CO}_{2}$ emissions in $\mathrm{S} 4$ is 16.7 kilotons. The proposed values of rail transit, bus, and taxi are the same as those in $\mathrm{S}^{\prime}$, because the $\mathrm{CO}_{2}$ emissions factors of bus and taxi have no influence on people's requirements of the travel time and the accessibility, which verifies the validity of the model from the side.

$S 1^{\prime}, S 2$, and $S 2^{\prime}$ versus $S 3, S 3^{\prime}$, and $S 4$. The proposed value for rail transit is low in $\mathrm{S}^{\prime}, \mathrm{S} 2$, and $\mathrm{S} 2^{\prime}$ and high in $\mathrm{S} 3, \mathrm{~S} 3^{\prime}$, and $\mathrm{S} 4$. Hence it is clear that with the development of the city, rail transit will lose competitiveness gradually in public transit system if there are no development of public transit and no rise in the accessibility of rail transit.

From what has been analyzed above, it is quite clear to see that MPMP can obtain the optimum ratios of rail transit, bus, and taxi and the lowest amount of $\mathrm{CO}_{2}$ emissions under certain restrict level due to the adoption of $T$ and $S$. In this case, the promotion of the "Oil replaced by Gas" project, thorough management in urban roads, and rapid development of public transit can all reduce $\mathrm{CO}_{2}$ emissions obviously, and the reduction effect can be measured by the amount of $\mathrm{CO}_{2}$ emissions. Therefore, this model can be used to analyze the effects of various policies under different restrict levels and provides basis for decision makers, which is a quite practical application of MPMP.

\section{Conclusion}

Aiming at the lowest $\mathrm{CO}_{2}$ emissions, an optimal allocation model of public transit mode proportion (MPMP) has been built in this paper. In MPMP, four constraint conditions have been considered: the traffic demand, the construction costs, the travel time, and the accessibility. By inputting some gettable and typical data, the optimal allocation model can generate the optimum ratios of passenger traffic that rail transit, bus, and taxi should undertake separately. And through the scenarios built based on Shanghai, a good application of the model has been presented, and more proportion of mass transit system is suggested.

There are mainly two applications of MPMP. The main application is to provide the optimum ratios of passenger traffic that different modes of public transit should undertake for the lowest $\mathrm{CO}_{2}$ emissions. According to the proposed values that MPMP generates, governments may guide the travel structure by some policies and managements to pursue the reduction of $\mathrm{CO}_{2}$ emissions. Besides, since MPMP adopts two parameters to restrict the service level of travel time and the accessibility, its output is under certain conditions. With different values of the parameters, the model can provide the outputs under various conditions, which allows us to analyze the impacts of various decisions and provide the basis for decision makers. That is the other practical application of MPMP.

This paper, which did not regard public transit as a whole, has tried a new perspective for the development of lowcarbon transportation. It looks every mode of public transit as a unit and tries to find a low-carbon way by studying the proportion of different public transit modes, which suggests to researchers a new way to try. However, this paper built the optimal distribution model from a point of macroscopic perspective, so some typical indexes have been ignored temporarily. For further study, the model can be developed from the point of macroscopic perspective into medium perspective, which means factoring other parameters like capacity and comfortableness in the model. The line length, density of network, site number, site coverage, and capacity of each vehicle, for example, can be considered and lead the output of the model to some dominant indexes such as the number of vehicles a bus line should be equipped with. And a system can be developed to quantify the comfortableness and add it to the constraint conditions of the model.

\section{Conflict of Interests}

The authors declare that there is no conflict of interests regarding the publication of this paper.

\section{References}

[1] U.S. Energy Information Administration (EIA), Transport, Energy and $\mathrm{CO}_{2}$, Moving towards Sustainability, 2009.

[2] L. Bailey, Public Transportation and Petroleum Savings in the US: Reducing Dependence on Oil, ICF International, 2007.

[3] A. Yoshida and N. Harata, "A mix-mode choice model including railway route, station and its access and egress modes choice," Journal of Infrastructure Planning and Management, vol. 542, pp. 19-31, 1996.

[4] B. Li and H. Tamura, "Estimation of a reduction in $\mathrm{CO}_{2}$ emissions by shifting commuters' travel mode from the private car to public transport," International Journal of Systems Science, vol. 34, no. 3, pp. 159-165, 2003.

[5] R. K. Bose, "Urban transport scenarios in South Asia: energy and environmental impact of enhanced public transport systems," Transportation Research Record, vol. 2011, no. 2007, pp. 116-126, 2008.

[6] R. Hickman, O. Ashiru, and D. Banister, "Achieving carbonefficient transportation: backcasting from London," Transportation Research Record, no. 2139, pp. 172-182, 2009.

[7] A. Mostashari, J. M. Sussman, and S. R. Connors, "Design of robust emission reduction strategies for road-based public transportation in Mexico City, Mexico-multiattribute tradeoff analysis for Metropolitan area," Energy and Environmental Concerns, vol. 1880, pp. 90-98, 2004.

[8] D. He, F. Meng, M. Q. Wang, and K. He, "Impacts of urban transportation mode split on $\mathrm{CO}_{2}$ emissions in Jinan, China," Energies, vol. 4, no. 4, pp. 685-699, 2011.

[9] T. Feng, J. Zhang, A. Fujiwara, and H. J. P. Timmermans, "An integrated model system and policy evaluation tool for maximizing mobility under environmental capacity constraints: a case study in Dalian City, China," Transportation Research Part D: Transport and Environment, vol. 15, no. 5, pp. 263-274, 2010.

[10] S. W. Wayne, J. A. Sandoval, and N. N. Clark, "Emissions benefits from alternative fuels and advanced technology in the U.S. transit bus fleet," Energy \& Environment, vol. 20, no. 4, pp. 497515, 2009.

[11] F. Gallivan, J. Ang-Olson, C. B. Liban, and A. Kusumoto, "Cost-effective approaches to reduce greenhouse gas emissions through public transportation in Los Angeles, California," Transportation Research Record, no. 2217, pp. 19-29, 2011. 
[12] M. Maciel, L. Rosa, F. Correa, and U. Maruyama, "Energy, pollutant emissions and other negative externality savings from curbing individual motorized transportation (IMT): a low cost, low technology scenario analysis in Brazilian urban areas," Energies, vol. 5, no. 3, pp. 835-861, 2012.

[13] S. Damart and B. Roy, "The uses of cost-benefit analysis in public transportation decision-making in France," Transport Policy, vol. 16, no. 4, pp. 200-212, 2009.

[14] Y. Huang, Y. Fan, and R. L. Cheu, "Optimal allocation of multiple emergency service resources for protection of critical transportation infrastructure," Transportation Research Record, no. 2022, pp. 1-8, 2007.

[15] W. Fan and R. B. MacHemehl, "Bi-level optimization model for public transportation network redesign problem," Transportation Research Record, no. 2263, pp. 151-162, 2011.

[16] W. Orabi and K. El-Rayes, "Optimizing the rehabilitation efforts of aging transportation networks," Journal of Construction Engineering and Management, vol. 138, no. 4, pp. 529-539, 2012.

[17] D. T. Barnum, M. G. Karlaftis, and S. Tandon, "Improving the efficiency of metropolitan area transit by joint analysis of its multiple providers," Transportation Research Part E: Logistics and Transportation Review, vol. 47, no. 6, pp. 1160-1176, 2011.

[18] W. Liu, "Analysis for the prospect of developing low carbon transport in Beijing," Integrative Transportation, vol. 9, pp. 3740, 2010.

[19] Shanghai Construction and Traffic Committee, Shanghai's Fourth Report of Integrated Traffic Survey, 2010. 


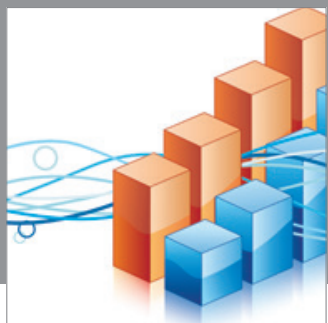

Advances in

Operations Research

mansans

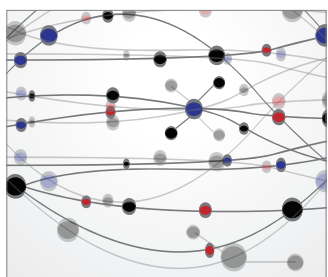

The Scientific World Journal
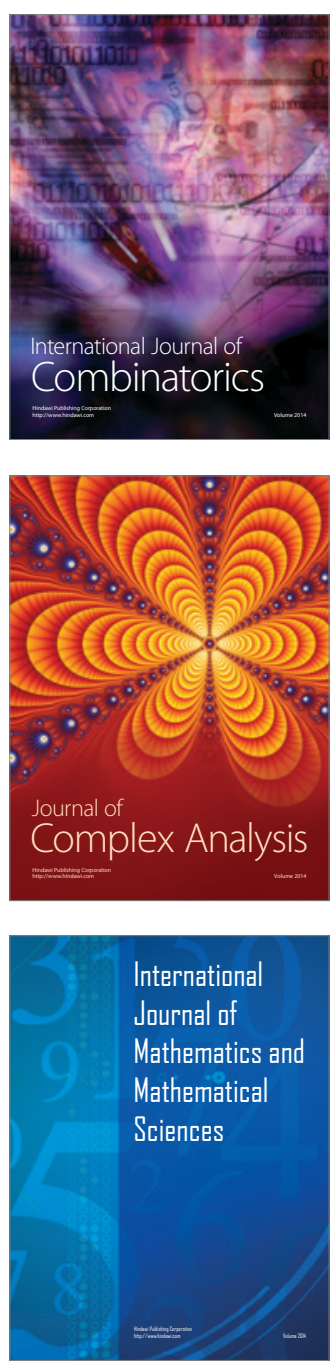
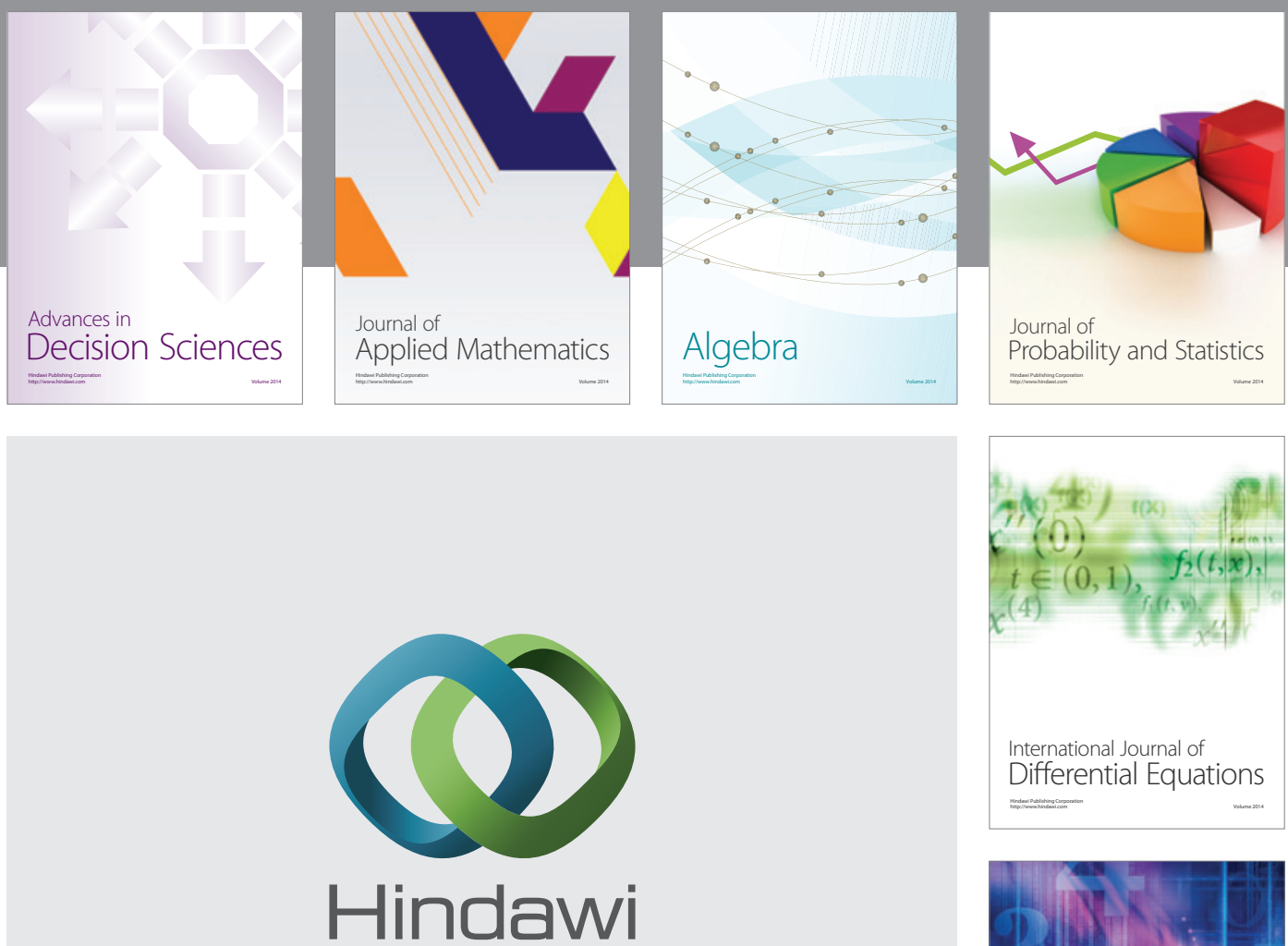

Submit your manuscripts at http://www.hindawi.com
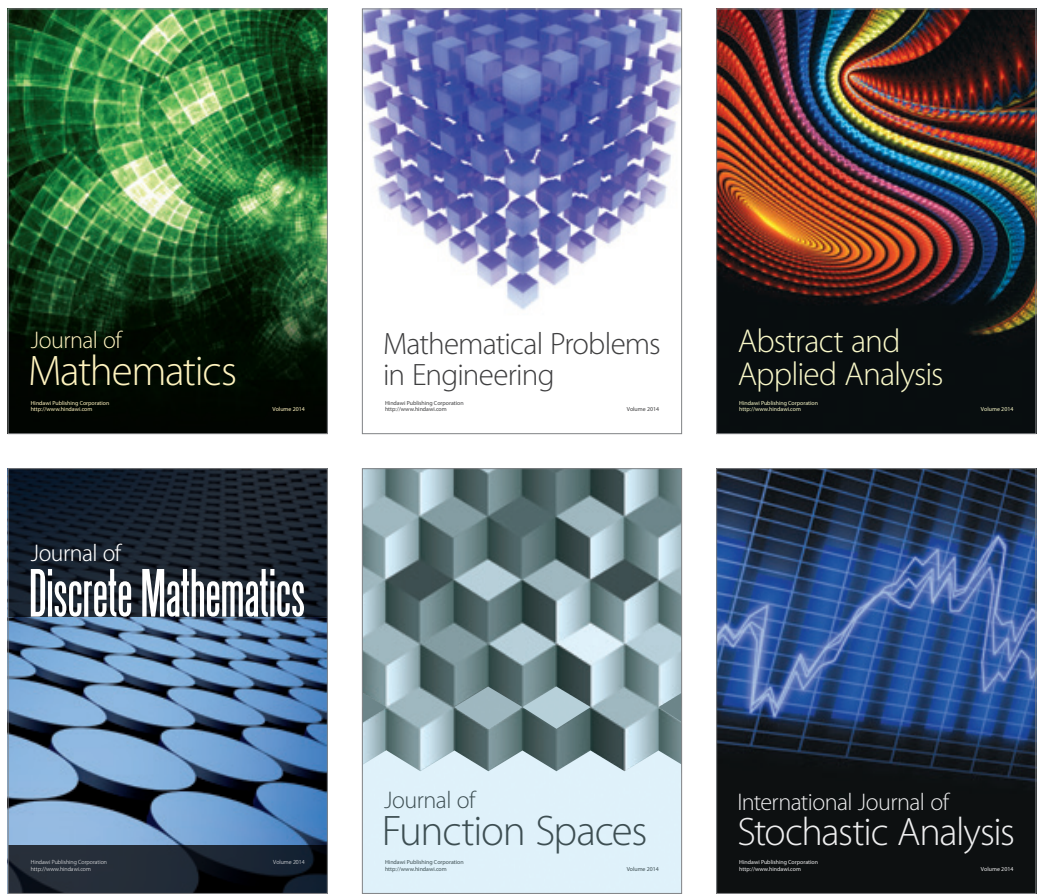

Journal of

Function Spaces

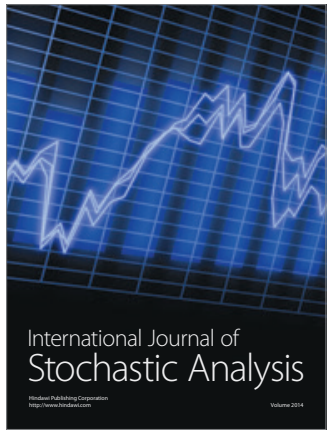

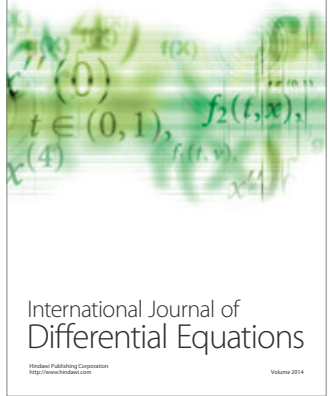
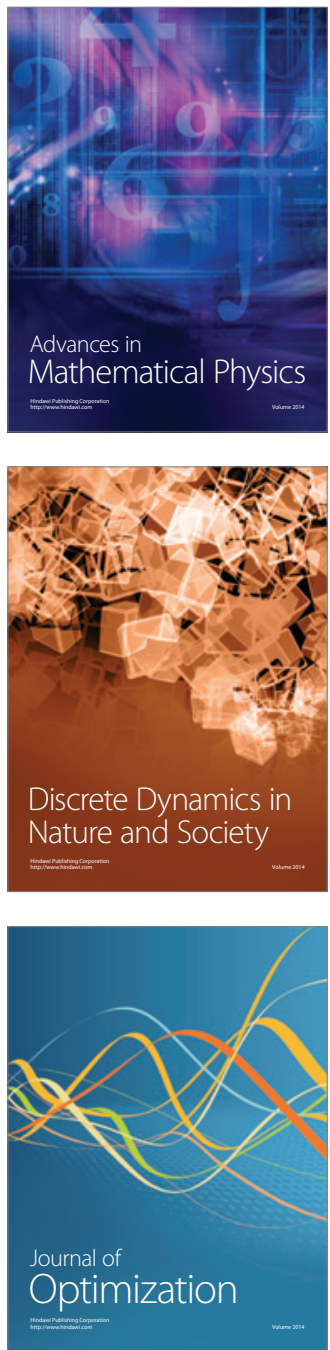